Francinaldo do Monte Pinto ${ }^{1}$

Paulo César Zambroni-de-Souza ${ }^{2}$

\section{A atividade de trabalho de motoristas de ambulância sob o ponto de vista ergológico}

\author{
The work activity of ambulance drivers from the ergological \\ point of view
}

\section{Resumo}

Objetivo: analisar a atividade dos motoristas de ambulância do Serviço Móvel de Urgência (SAMU). Métodos: foi empregada a perspectiva ergológica, que se opera a partir da concepção de vida-saúde-doença postulada por George Canguilhem, e a Ergonomia da Atividade. Foram realizadas onze entrevistas dialógicas com motoristas da Unidade de Terapia Intensiva Móvel, em 2010, no estado da Paraíba. Resultados: os motoristas atribuem as principais dificuldades para realizar o trabalho ao modo de organização prescrita do trabalho no SAMU, à gestão temporal da atividade, à atividade no trânsito, à relação com a população usuária e ao risco de contrair doenças. Em contraposição, os motoristas adquirem sentido no trabalho ao salvarem vidas, em uma conjunção de valores - solidariedade, confiança e cooperação - em relação aos socorridos e aos seus acompanhantes. Quando essa possibilidade não se concretiza, o coletivo de trabalho serve de apoio para que permaneçam na profissão, apesar das frustrações. Conclusão: evidenciou-se que, mesmo diante das variabilidades cotidianas da atividade de trabalho, os motoristas de ambulâncias produzem modos operatórios para dar conta das situações de trabalho, cooperando para solução dos problemas e/ou manejando as imprevisibilidades no trabalho em equipe.

Palavras-chave: trabalho; transportes; saúde do trabalhador; gerenciamento da prática profissional.

\begin{abstract}
Objective: to analyze the work activity of ambulance drivers of the Urgent Medical Aid Service (SAMU). Methods: an ergology-based study which operates according to the conception of life-health-disease postulated by Georges Canguilhem and Activity Ergonomics was carried out. Eleven dialogical interviews were conducted with drivers from the Mobile Intensive Care Unit of Paraíba state, Brazil, in 2010. Results: according to the drivers interviewed, the main difficulties to realize their work result from the organizational way in which the work is prescribed by $S A M U$, the management of time during the activity, the traffic intensity, the relationship with the service users, and the risk of being contaminated by diseases. In contrast, ambulance drivers acquire meaning to their work when they are able to save lives, within a combination of factors - solidarity, trust and cooperation. When these possibilities are missing, the working group serves as a support for those ambulance drivers who want to remain in their profession despite their frustration. Conclusion: it was possible to observe that, even facing the daily variability of work, ambulance drivers develop operating ways to handle their work situations, cooperating to the solution of problems and/or adjusting to the unpredictability within the teamwork.
\end{abstract}

Keywords: work; transportation; occupational health; practice management. 


\section{Introdução}

A atividade de trabalho dos motoristas de ambulância pode ser considerada um tema relativamente explorado na literatura científica. Pudemos observar, em pesquisas realizadas anteriormente, um conjunto de fatores relacionados à presença da nocividade dos ruídos do tráfego (frequência, pressão sonora, duração da exposição diária e sensibilidade de cada motorista a essas exposições); aos sintomas osteomusculares e aos consequentes riscos ergonômicos originários das inadequações dos equipamentos auxiliares para transporte de pacientes; aos riscos e ocorrências de acidentes; à falta de treinamento periódico da equipe de trabalho (motorista, enfermeiro, técnico de enfermagem e médico); e, por fim, à prevalência e aos fatores associados à Sonolência Excessiva Diurna em condutores de ambulância.

O ruído do tráfego é considerado um dos principais responsáveis pela poluição sonora, sendo bastante discutido nos diversos meios de comunicação de massa, bem como em publicações científicas (SILVA; GOMEZ; ZAHER, 2006), evidenciando uma série de alterações ou efeitos nocivos à audição e à saúde em geral. Sanches (2003) acrescenta que as fontes de ruído são decorrentes dos automóveis, ônibus, sirenes de polícia e ambulância, ocasionando importantes prejuízos à saúde física e mental. Marques (1998) chama a atenção para a possibilidade de uma deficiência visual ou auditiva nos motoristas profissionais acarretar danos não somente à sua integridade física, mas também à das pessoas que estão sendo conduzidas por ele, além do risco para os pedestres que circulam pelas ruas.

As pesquisas sobre as inadequações ergonômicas relacionadas aos equipamentos auxiliares para o transporte de pacientes em ambulâncias apontam uma série de diferenças entre a altura da cama e da maca, cadeiras de rodas e macas de difícil movimentação. Além disso, a falta de travas em macas e camas dificulta a remoção dos pacientes pelas equipes de trabalho. Esses aspectos foram observados por Célia e Alexandre (2004) em trabalhadores da área de saúde de um Serviço de Transportes de Pacientes (equipe de enfermagem, motoristas, escriturários e guardas), responsáveis pela execução de transportes intra e intermunicipais. Os resultados da pesquisa indicam a ocorrência elevada de sintomas osteomusculares em diferentes partes do corpo, particularmente na coluna vertebral e na região lombar. Apontam como possíveis causas desses acometimentos, os fatores ergonômicos, a saber: camas e macas sem alturas ajustáveis, macas não retráteis, falta de equipamentos auxiliares, dificuldades de acesso e de locomoção no interior de residências, equipamentos inadequados e sem manutenção e ausência de treinamento da equipe.
Nessa mesma direção, Rossi, Rocha e Alexandre (2001) realizaram uma pesquisa sobre os aspectos ergonômicos com trabalhadores de uma central de transportes de um hospital universitário. Os resultados apontaram o nível de dificuldades da equipe de "escolta" do hospital quanto ao deslocamento de pacientes da cama para a cadeira de rodas e vice-versa, da cama para maca e vice-versa, da maca para a ambulância e da ambulância para a maca. Foram percebidos alguns problemas nos equipamentos utilizados para a transferência de pacientes pela equipe, assim como posturas inadequadas desses trabalhadores durante a transferência de pacientes.

As investigações de Pereira e Lima (2006) e Takeda e Robazzi (2007) acerca das ocorrências de acidentes de trabalho, respectivamente com motoristas de ambulâncias de um serviço de atendimento pré-hospitalar e de um serviço de socorro de urgências, indicam a necessidade de prevenção, qualificação e treinamento dos profissionais que prestam socorro de urgência. Além disso, assinalam os autores, estes profissionais enfrentam o risco de acidentes devido à sonolência, à fadiga e à exposição aos agentes de riscos físicos, químicos, biológicos e às situações antiergonômicas dos equipamentos utilizados na remoção dos pacientes.

Por último, Ambrósio e Geib (2008), investigaram os fatores que incidem sobre a Sonolência Excessiva Diurna (SED) em condutores de ambulância da Macrorregião Norte do Estado do Rio Grande do Sul. Com esse propósito, os autores concluíram que a abstinência do sono, estudada em 105 condutores de veículos de serviços públicos de saúde, pode colocar em risco os usuários do Sistema Único de Saúde, inclusive os próprios motoristas de ambulâncias. Ademais, a sonolência diurna foi associada com apneia e roncos, indiferente às variáveis sociodemográficas, padrões de sono, condições de saúde e estilo de vida. Em síntese, apesar da predominância do grau de sonolência leve encontrado na pesquisa, a maior preocupação indicada pelos autores esteve voltada para os motoristas com vínculo funcional efetivo e/ou portadores de apneia do sono, principais fatores associados à SED.

Quando se direciona o interesse para a atividade e a gestão no trabalho desses profissionais, fica evidente a ausência de investigações associadas à questão da saúde, às normas e aos procedimentos requeridos para sua atuação em situações de socorro àqueles que necessitam do serviço de urgência médica.

Compreender o modo de trabalhar desses motoristas se mostra particularmente importante, na medida em que se observa sua ação profissional na sociedade com a atribuição de salvar vidas, defrontando-se com o barulho da sirene, riscos de acidentes, má condição das vias, rapidez de velocidade do veículo e atenção constante aos sinais de trânsito e a outros veículos. Sob tais circunstâncias, exigem-se desses profissionais 
astúcia, engenhosidade e inteligência, que vão além do cumprimento de normas preestabelecidas. Nesse contexto, entra em jogo a dimensão de valores (imensuráveis) da ordem do viver, do que é saúde, solidariedade e justiça. É nessa busca de compreensão e análise da atividade dos motoristas que nos inspiramos na perspectiva ergológica.

Por meio do conceito de atividade, como propulsor de debates de normas e valores em situações de trabalho, a ergologia desenvolve seu conjunto de proposições sobre a atividade humana. É com esse conceito-chave, igualmente adotado por outras disciplinas teóricas, que esse ramo da etnologia se propõe a fazer uma espécie de sinergia com outras disciplinas e abordagens em que o conceito de atividade não estava ausente, mas continuava conceitualmente pouco evidenciado.

No caso da contribuição do filósofo George Canguilhem, inspiração central para o pensamento ergológico (ao lado de Ivar Oddone e Alain Wisner), destacamos outra concepção da noção de saúde, que privilegia o estudo das anomalias, das monstruosidades, das variações, dos erros, das infrações e das infidelidades apresentadas pelo meio. Isso significa que pensar um conceito de saúde, a partir das variações e das anomalias, supõe negar-se a aceitar uma concepção com pretensão de valor universal (CAPONI, 1997). De acordo com Canguilhem (1995, p. 130), "normal” é viver em um meio em que flutuações e novos acontecimentos sejam possíveis; é a possibilidade de ficar doente e poder recuperar-se:

Ser sadio significa não apenas ser normal numa situação determinada, mas ser, também, normativo, nessa situação e em outras situações eventuais. O que caracteriza a saúde é a possibilidade de ultrapassar a norma que define o normal momentâneo, a possibilidade de tolerar infrações à norma habitual e de instituir normas novas em situações novas. (CANGUILHEM, 1995, p. 158)

É preciso deixar claro que o "normal” (CANGUILHEM, 1995, p. 130) não tem uma rigidez que seja válida para toda espécie. O que existe é a flexibilidade de uma norma que se transforma em relação às condições individuais. Por isso, se constata a imprecisão estabelecida entre o limite do normal e do patológico. Assim, podemos concluir, com base em Canguilhem (1995), que a saúde implica muito mais que a possibilidade de viver em conformidade com o meio externo, implica, principalmente, a capacidade de instituir novas normas. No caso dos motoristas de ambulância pesquisados, apontamos um tipo particular de gestão do trabalho que consiste, sobretudo, na capacidade de criar novas normas, de fazer desvios, tomar novas direções, fazer escolhas inusitadas frente ao inédito, dando conta, mesmo que provisória e parcialmente, da complexidade da vida e do trabalho.

Reportando-se à Ergonomia da Atividade, outro pilar de edificação da perspectiva ergológica, pontuamos a contribuição dessa disciplina para o conceito de atividade, oriundo da discrepância entre o trabalho prescrito/tarefa e o trabalho real/atividade (GUÉRIN, et al., 2001; DARSES; MONTMOLLIN, 2006; BRITO, 2006). Com essa diferença, os ergonomistas deram mais visibilidade à face oculta do trabalho projetado pelo Sistema Taylor. Assim, não obstante os trabalhadores não executassem exatamente o que fora prescrito, eles não poderiam ser chamados de indisciplinados, irresponsáveis ou incapazes de compreender e aplicar a prescrição ao pé da letra. Isso significa que, na realização da tarefa, o trabalhador - individual e coletivamente - depara-se com equívocos e limites de qualquer prescrição, com o acaso e com inúmeras formas de variabilidades: panes, dificuldades de previsão, disfuncionamentos, diferenças de ritmo, efeitos da idade e da experiência acumulada. Mesmo nas atividades ditas mais simples e pretensamente automatizadas, pressupõe-se uma exigência mental (constante e inelutável), sem a qual nenhum sistema produtivo poderia funcionar (TEIGER, 1993), já que todo trabalho mobiliza necessariamente a inteligência (WISNER, 1994).

Em função dos aspectos reportados, chama a nossa atenção o modo como os motoristas, ao realizarem sua atividade, lidam com a dimensão dos valores e como esses valores adquirem importância na forma de gerir o trabalho cotidiano. Diante desse contexto, o objetivo deste trabalho foi analisar a atividade dos motoristas de ambulância a partir do ponto de vista ergológico.

\section{Procedimentos metodológicos}

Para a realização da pesquisa nesse campo empírico, Serviço de Atendimento Móvel de Urgência (SAMU), contatamos a Secretaria de Saúde do Município, que nos encaminhou ao setor de Gerência de Educação em Saúde para entrega e posterior avaliação do projeto de pesquisa. Recebemos a carta de autorização do referido órgão para ser entregue ao Coordenador do SAMU. Ao contatá-lo, fizemos a exposição dos motivos e dos interesses em realizar a pesquisa naquela empresa, devidamente identificados com as cartas de anuência da Secretaria da Saúde e do Comitê de Ética em Pesquisa, emitido pelo Centro Universitário de João Pessoa em 2010. Por fim, obtivemos o aval para iniciar efetivamente o estudo de campo no SAMU. A participação de todos levou em consideração os aspectos éticos pertinentes à investigação que envolve seres humanos.

Foram entrevistados onze motoristas de ambulâncias do SAMU de uma cidade do estado da Paraíba. A amostra foi intencional, tendo sido definida e contactada a partir de visitas ao serviço, nos diversos dias da semana, nos três turnos (manhã, tarde e noite). 
O critério de inclusão para participar da pesquisa foi determinado pelo interesse de cada profissional, que, voluntariamente, assinou o termo de consentimento livre e esclarecido. Não houve critério de exclusão que não fosse o desinteresse em participar, mas desde o primeiro contato, ninguém se negou a participar da pesquisa. Os entrevistados são casados, exceto um que se declarou divorciado, na faixa etária entre 28 e 50 anos, cursaram o ensino médio completo e já atuam na profissão entre dois a oito anos.

No processo de investigação, partimos do pressuposto de que, para pensar a atividade de gestão do trabalho dos motoristas de ambulância, é necessário ter como elemento fundamental de análise os saberes constituídos nessa categoria profissional, incorporados à produção de conhecimento sobre esse campo durante a gestão no trabalho. Para isso, adotamos como dispositivo metodológico um meio indireto de acesso à atividade dos motoristas, denominado entrevista dialógica.

Na condução das entrevistas dialógicas, intermediadas por contatos e visitas ao local da pesquisa, tomamos como foco a condensação de diferentes situações de enunciados produzidos pelas conversas cotidianas sobre o trabalho. Desse modo, caracterizamos a entrevista como dispositivo enunciativo e rejeitamos o ponto de vista que nela reconhece tão somente o papel de mera ferramenta, que possibilitaria ao entrevistador o acesso à "verdade" do entrevistado (ROCHA; DAHER; SANT'ANNA, 2004).

\section{Entendemos que a entrevista é}

[...] uma nova situação de enunciação que reúne entrevistador e entrevistado, situada num certo tempo, num espaço determinado, revestida de um certo ethos, com objetivos e expectativas particulares, etc. (ROCHA; DAHER; SANT'ANNA, 2004, p. 174)

As entrevistas foram transcritas para que os pesquisadores pudessem reler repetidamente os materiais, em busca de melhor apreensão dos saberes produzidos naqueles diálogos, estabelecendo, dessa maneira, uma " [...] interlocução com uma dada massa de textos que possuem uma lógica própria" (ROCHA; DAHER; SANT'ANNA, 2004, p. 169). A estratégia estabelecida na presente pesquisa foi lançar luz aos elementos de valoração do trabalho analisado a partir dos diálogos transcritos, o que permitiu-nos evidenciar os aspectos ligados à inserção profissional, ao modo de gestão dessa atividade e às relações existentes entre os membros de uma mesma equipe. Vale ressaltar que as pausas encontradas nos fragmentos das falas foram codificadas pelo uso de reticências. Para manter o anonimato dos motoristas, adotamos nomes fictícios.

Para melhor compreender o trabalho dos motoristas, no atravessamento entre o trabalho prescrito e o real e, assim, avançar para as normas antecedentes e as renormatizações, elaboramos um roteiro de entrevista que propiciasse um diálogo com os motoristas sobre o histórico profissional, a descrição de um dia de trabalho, as relações de trabalho com a equipe e com os usuários, os valores mobilizados em situações de urgência e emergência móvel.

O tratamento do material, categorizado de forma temática, foi organizado em cinco eixos: inserção profissional, cotidiano do trabalho, gestão da atividade de trabalho, relações de trabalho e dimensão dos valores no trabalho.

\section{Resultados e discussão}

Nas pesquisas relacionadas ao trabalho de motoristas de ambulâncias citadas na Introdução deste artigo, evidenciamos problemas audiológicos provocados pelo ruído do trânsito, aspectos ergonômicos de inadequações dos equipamentos auxiliares das ambulâncias que provocam alterações e dores na coluna vertebral e na região lombar dos motoristas, presença eminente de riscos de acidentes de trabalho oriundos das condições de trabalho e da Sonolência Excessiva Diurna durante o trabalho desses profissionais. A maioria das pesquisas utiliza métodos estatísticos que permitem comparações entre "fatores causais" (em uma relação causal simples), como exemplo: a frequência de exposição do ruído provoca diminuição ou perda auditiva dos motoristas de ambulâncias; a inadequação ergonômica dos equipamentos auxiliares na remoção de pacientes acarreta dores na região lombar e na coluna vertical.

No entanto, não observamos, no conjunto dos materiais de pesquisa, evidências de análises que considerem os saberes e experiências vividos na atividade de trabalho dos motoristas de ambulâncias. Também não verificamos uma preocupação com o modo de trabalhar desses profissionais de saúde no tocante aos valores que perpassam sua atividade, fatores esses que são o foco da presente pesquisa.

\section{Eixo 1 - Inserção profissional: a escolha da profissão}

Para o primeiro tema, relacionado à escolha da profissão de motorista de ambulância, os participantes relataram os motivos pelos quais se tornaram motoristas, ou como preferem ser chamados, condutores de ambulância. Vejamos os principais relatos selecionados sobre isso:

Eu gosto dessa atividade, de salvar vida, adrenalina. Sempre gostei. (Pedro)

Porque eu gosto da profissão e porque eu gosto do eu faço. Então trabalho no SAMU porque eu amo ajudar as pessoas. O que eu mais gosto é, sabe? Que eu posso contribuir prá que uma pessoa [...] possa se 
sentir melhor após um acidente, entendeu? Depois de alguma outra coisa de ruim que a gente possa ajudar e ela possa ficar boa. (Carlos)

O interesse em trabalhar na área, porque senti afinidade e desejo de exercer a função. (Luis)

Um pouco de necessidade, serviço mesmo. Eu queria ser músico, mas a vantagem não é boa. Instrumento, toquei muito em banda de forró, mas é aperreio. (João)

Prefiro gostar do que você faz e ter amor à profissão. Atualmente tenho uma renda aqui e em outro lugar, mas eu trabalho mesmo aqui. Você vê a importância da gente chegar a uma ocorrência, vê que a pessoa tá precisando de ajuda. Prá mim é muito importante, eu me sinto assim, realizado fazendo esse trabalho. (José)

Porque eu gosto. Eu senti na minha veia, o sangue correr nas minhas veias, e via mesmo que o sangue era laranja e vermelho. Antes de trabalhar no SAMU eu já era motorista da secretaria de saúde, dirigia para o secretário de saúde, antes dela eu já dirigia e fiz o curso de Geografia na Federal e fiz educação física, e nessa parte de educação física a gente vê a parte de anatomia, aquelas coisas, e eu sempre gostei desse negócio de corpos, de órgãos também, nunca tive problema não, daí quando vi o SAMU me apaixonei logo só pelo nome, eu tinha como entrar no SAMU. (Marcos)

Observa-se, nas falas acima, que o principal motivo da inserção profissional está relacionado ao ato de salvar vidas, ajudar outras pessoas. Esse motivo pode ser remetido ao que Schwartz (2005) denomina de valores sem dimensão, enraizados nas situações singulares e históricas da vida, mais ou menos universais, como exemplo do bem comum. O salvar vidas, enunciado pelos condutores, remete a um valor nobre direcionado a cada pessoa de modo diferente, tanto no trabalho quanto fora dele.

Em relação à expectativa da profissão, buscamos conhecê-la sob dois pontos de vista: antes e depois da inserção profissional. Partimos da premissa de que o processo de "escolha" da profissão não é originado por uma vocação. Ao contrário disso, é permeada por uma mescla de valores - quantificáveis e não quantificáveis - oriundos da relação entre o sujeito e os grupos sociais, sem qualquer garantia dessa concretização de expectativa no futuro. Isso implica dizer que a realidade do trabalho coloca à prova os desejos e os sonhos construídos na escolha da profissão.

Vejamos o que eles responderam:

É a mesma de antes [referindo-se às expectativas], a gente vê, assim, quando você tá de fora, você vê de uma maneira e quando tá de dentro vê de outra maneira. Quando tá lá de fora pensa que o SAMU só vai para ocorrências gravíssimas, mas, na verdade, não é como a gente pensa, a gente vai prá caso clínico, atendimento de família, atendimento psiquiátrico, vários atendimentos. (José)

No começo a gente quer conhecer o novo. Hoje não, hoje é mais tranquilo, o risco; no começo é mais aventura, hoje não, eu sempre gostei de esporte radical [...] hoje eu levo mais para o lado profissional. (João)

\section{Eixo 2 - Cotidiano de trabalho}

Compete ao motorista de ambulância do SAMU: condução imediata ao local do chamado, quando acionado, pilotando a ambulância com segurança; ser capaz de reconhecer situações de risco e solicitar auxílio à base do SAMU via rádio, expondo de forma clara e objetiva a situação no local da ocorrência; realizar manobras técnicas que garantam a sobrevivência do paciente até a chegada da equipe de atendimento completa do SAMU; auxiliar, quando solicitado, a equipe médica e de enfermagem no atendimento aos pacientes no local da ocorrência; transportar pacientes em macas, pranchas e similares, segundo técnicas específicas, do local da ocorrência para as ambulâncias e destas para os hospitais ${ }^{3}$. (SANTA CATARINA, 2012)

Considerando que a atividade de trabalho consiste em um esforço de adaptação à situação real de trabalho, entremeada pelo hiato entre o prescrito e o real (GUÉRIN et al., 2001), os motoristas entrevistados concebem o dia a dia de trabalho utilizando-se das expressões "bons dias de trabalho" e "maus dias de trabalho".

Um dia bom de trabalho é quando tem ocorrência que a gente entra em sintonia [com] todo mundo, consegue salvar vidas, de 10 ocorrências a gente salva 9, isso aí é gratificante demais até porque quando a gente salva durante o caminho mesmo, o trajeto até o hospital, quando a gente chega com essa vítima salva lá, ressuscita uma pessoa de uma parada e a gente consegue salvar, isso aí é gratificante demais. (Marcos)

Um bom dia para mim de trabalho é acordar, vim trabalhar com a mente aberta e pensar em chegar ao trabalho independente das situações adversas, mas o foco maior é no que você vai fazer, você tem que deixar seus problemas particulares em casa e focar no seu trabalho. Eu venho com o intuito de trabalhar. Tem dia que você fica, rapaz! Não peguei uma ocorrência, mas se for acionado eu vou. Às vezes mesmo não sendo minha área eu vou. Eu digo: oh! Estou em QAP total, que quer dizer pronto para atender à solicitação da central. Então para mim um bom dia de trabalho independe de ter muitas ou poucas ocorrências. (Luís)

Um dia bom de trabalho é quando a gente não tem muitas ocorrências. (Carlos)

Quando tem poucas ocorrências e o serviço é tranquilo. (Fausto)

\footnotetext{
3 As atribuições dos profissionais do SAMU, conforme orientação do coordenador do órgão local, encontram-se detalhadas, inclusive para fins de treinamento da equipe, no Regimento Interno da Secretaria de Saúde do Estado de Santa Catarina (SANTA CATARINA, 2012).
} 
Um dia sem intrigas, por que às vezes acontece. (Reginaldo)

Um dia bom mesmo é quando está tudo tranquilo, assim a gente não deseja mal para ninguém. Eu desejo a paz, que ninguém tenha doença. (José)

Observa-se, nesses fragmentos de falas, que os motoristas atribuem um valor positivo à realização do trabalho. Eles demonstram a centralidade do trabalho em suas vidas, independentemente das ocorrências, posto que almejam alcançar o objetivo primeiro: salvar vidas. Por outro lado, compartilham de algumas normas antecedentes, não fixadas nas atribuições de motorista de ambulância, quando se referem à execução de um trabalho "sem intrigas, serviço tranquilo". Isso implica dizer que a gestão do trabalho desses motoristas, na medida em que visa favorecer a sua saúde e a de outros, não pode ignorar as características do meio de trabalho e dos seres humanos (aqui remetido aos próprios colegas), como esforço para viver. (SCHWARTZ, 2005)

As diferenças nas falas mostram as diferenças nos valores dos motoristas, havendo aqueles que valorizam mais o trabalho bem feito, o salvar vidas ("de 10 ocorrências a gente salva 9, isso aí é gratificante demais"), mesmo que isso certamente acarrete maior cansaço no fim do plantão e, possivelmente, alguns problemas de saúde (MARQUES, 1998; CÉLIA; ALEXANDRE, 2004; ROSSI; ROCHA; ALEXANDRE, 2001). Outros preferem os dias menos movimentados ("Quando tem poucas ocorrências e o serviço é tranquilo"), o que não significa que deixem de atender as ocorrências quando necessário, uma vez que permanecem "com o intuito de trabalhar". Nesse caso, podemos entender que o dia com poucas chamadas representa menos desgaste para os condutores, mas também para os cidadãos, que teriam sofrido menos acidentes ("assim a gente não deseja mal para ninguém”), reforçando assim o valor do bem estar alheio.

Por outro lado, como veremos abaixo, consideram que um dia sem ocorrências pode ser considerado um dia ruim. Ao lado disso, há quem coloque importância na relação com os colegas ("Um dia sem intrigas, por que às vezes acontece"), ressaltando que o coletivo tem uma função primordial para o bem comum (SCHWARTZ, 1998, 2000). É a conjugação comum desses valores, apesar das diferenças, que permitirá a construção de Entidades Coletivas Relativamente Pertinentes (SCHWARTZ; DURRIVE, 2010) capazes de permitir a cada um manter sua saúde e desenvolver sua competência, desenvolvendo também a solidariedade no grupo, afinal "um dia ruim é quando a equipe não se entende" (Marcos).

De outro modo, os trabalhadores apresentam queixas e insatisfações sobre o que consideram um dia "ruim" de trabalho. Destaca-se, nas falas abaixo, como uma das dificuldades para trabalhar, a insuficiência das condições de trabalho.

Um dia ruim é quando a equipe não se entende, um dia ruim é quando as viaturas se quebram, que fica faltando viatura para entender a população, sobrecarrega as outras viaturas, uma viatura quebrada ela deixa de atender 100.000 habitantes, ela deixa de atender uma área de 50 a 100.000 habitantes, então você veja a noção do que é quebrar uma viatura, uma viatura estando parada no SAMU. (Marcos)

Um dia ruim é assim: tem muitas coisas adversas, então para quem gosta do trabalho no SAMU não tem dia ruim. (Luís)

Quando você sai por trote, muitos trotes são péssimos. (Miguel)

Quando tem eventos, trabalho dobrado e sem ganhar extra. Dia bom: Quando tem pouca ocorrência e o serviço é tranquilo. Incomoda: viatura sem condições. (Fausto)

Quando não existe ocorrência prá gente, porque a gente fica parado sem ter ocorrência. Quando acontece alguma coisa estressante procuro me acalmar e tentar resolver conversando com o coordenador para que possa tomar as medidas. (Carlos)

Quando de um paciente fica preso nas ferragens. Como a gente ainda não tem a tesoura, a mecânica, aí a gente tem que pedir ajuda dos bombeiros para efetuar o atendimento, porque aí tem que cortar a lataria do carro todinho, tem que ter o material que a gente não tem. (José)

Essas declarações sinalizam três aspectos: as variabilidades emanadas nas ocorrências, as condições insatisfatórias de trabalho e, por último, em decorrência desses dois aspectos, a impotência dos motoristas frente à plena realização de um atendimento móvel com qualidade e segurança. Ressaltamos que a queixa de Fausto, "viatura sem condições", coincide com o que apontam Célia e Alexandre (2004), assim como Rossi, Rocha e Alexandre (2001), ao mostrar a inadequação dos equipamentos disponíveis às equipes de socorro.

Vale esclarecer que a ênfase dada às variabilidades não tem o propósito de suprimi-las. Pelo contrário, “[...] a análise do trabalho permite compreender como os operadores [trabalhadores] enfrentam as diversidades e as variações de situações, e quais consequências trazem para sua saúde e para a produção" (GUÉRIN, et al., 2001, p. 49). Um exemplo que ilustra essa situação, declarado por Miguel, são ligações anônimas da população ao SAMU, assim como a fala de José:

[...] a gente foi atender um caso de hiperglicemia, quando chegou aqui na BR, aí dei de cara com um cara ao solo. Tinha umas pessoas lá no local. No que a gente tava passando viu essa ocorrência. $O$ que a gente fez? A gente lateralizou ele [o acidentado de moto], retirou o capacete dele e esperou o apoio da PRF [Polícia Rodoviária Federal], porque a polícia federal trabalha com a gente. Aí a gente esperou o 
procedimento e prosseguiu porque a viatura lá não era grave, mas o paciente que tava na moto, ele não podia nem respirar porque estava com secreção na boca. (José)

Cabe esclarecer que as más condições das vias e a falta de cooperação no trânsito, por parte de outros motoristas, além das variabilidades habituais (engarrafamentos, horários de pico, chuva, entre outros), dificultam a ação rápida desses profissionais no trajeto para as ocorrências. Isso, segundo os motoristas entrevistados, gera, na população, um descrédito em relação ao serviço do SAMU. Esse também é um fator que gera insatisfação nos motoristas e os leva a questionar sobre as expectativas no trabalho, como falou Thiago: "Nos acompanhantes o que menos agrada é você fazer tudo pra chegar num local e quando chega é criticado" (Thiago).

\section{Eixo 3 - Gestão da atividade de trabalho}

Quanto à gestão da atividade de trabalho, observamos que os entrevistados convivem constantemente com imprevistos e variabilidades ocasionados nos atendimentos móveis de urgência e emergência. Afinal, “[...] a gestão, como verdadeiro problema humano, advém por toda parte onde há variabilidade, história, onde é necessário dar conta de algo sem poder recorrer a procedimentos estereotipados" (SCHWARTZ, 2004, p. 23). Seguindo-se essa concepção gestionária, os motoristas expressam o modo como antecipam as normas de trabalho, frente às situações imprevistas aos chamados de atendimento.

Uma ocorrência: você chega lá, atendimento no local, aquela coisa bonitinha, tem ocorrência que não, que tem situação adversa como o povo brigando no meio da rua, e a população não entende, pergunta: aah por que demorou? A população não entende. Às vezes você fez rápido, arriscou sua vida, mas a população não entende. Acabou de ligar, e quer que a ambulância esteja de uma hora pra outra. (Pedro)

Nesses relatos, os motoristas mobilizaram outros modos de realizar o trabalho. À luz da perspectiva ergológica, eles renormatizaram o procedimento de socorro ao fazer escolhas e combinações que escapam à norma habitual de atendimento aos chamados da população. No dizer de Schwartz (2004, p. 23), “[...] toda gestão supõe escolhas, arbitragens, uma hierarquização de atos e de objetivos, portanto, de valores em nome dos quais essas decisões se elaboram.”

Essa renormatização pode ser percebida na relação com o trânsito, quando os motoristas mobilizam, durante as idas e vindas pela cidade, rapidez e agilidade para chegar o mais breve possível aos locais designados pela Central de Regulação às ocorrências. Nessas situações, eles fazem a gestão temporal da atividade, como podemos acompanhar nestas falas:
Quando o motorista está na frente e não dá a mão, espero até que ceda e sigo em frente, não ultrapasso sinal vermelho, pois posso por a minha própria vida e dos companheiros em risco. Alguns motoristas são solidários. (Paulo).

Em caso de emergência quando não tem pressa não ligo a sirene [...] primeiro boto o mapa na cabeça, depois peço mais informação. (Thiago)

No trânsito, tranquilo! Eu sou tranquilo, não me apavoro, nem estresso, tenho sangue frio [atua há 13 anos] [...] incomoda quando o condutor vê a sirene e não sai da frente. (Miguel)

\begin{abstract}
Na estratégia de condução, há as vias, vai primeiro pelas vias. Tenho oito [referindo ao tempo na profissão], sei quais as vias, transito, prefiro às vezes as vias longas do que as curtas por causa do trânsito. Eu vejo como tá fluindo o trânsito para que não haja perigo para a equipe e o paciente, interdito a rua todinha. (João)
\end{abstract}

\section{Eixo 4 - A tessitura de relações no trabalho}

O trabalho dos motoristas de ambulância é realizado em conjunto com outros profissionais (médico e técnicos de Enfermagem), sobretudo por ser uma atividade que requer um constante diálogo entre os próprios motoristas, usuários e acompanhantes. Dessa relação depende, em grande parte, o modo de reconhecimento no trabalho dos motoristas. Afinal, o trabalho como uso (e não, como mera execução) é atravessado pela presença de outros, como os colegas de trabalho, a direção da empresa, a sociedade em geral. Como assinala Schwartz e Durrive (2010, p. 192), “[...] a maneira pela qual eu trabalho diz qualquer coisa da sociedade na qual eu quero viver.”

Vejamos como essas relações se apresentam na visão de cinco motoristas profissionais do SAMU:

Tem que ser boa, é boa mesmo, é uma equipe. Me agrada quando as pessoas aplaudem, reconhecem. Desagrada quando a população diz que você atrasou. (Miguel)

A minha relação é harmoniosa, prazerosa, a gente brinca, tem um diálogo mais fácil, por eu ser um condutor antigo eles procuram me escutar também, às vezes eu me envolvo, eu digo: companheiro, vamos fazer desse jeito da próxima vez? Procure fazer assim. Ele mesmo me procura, sabe? Pra pedir uma explicação, tirar uma dúvida, aí eu sempre ajudo no que eu posso, eu tô ajudando ele. (Marcos)

Tenho ótima relação com meu chefe, o que me agrada [nos usuários] é o bom atendimento quando a gente chega no local [...] a gente usa um pouco de psicologia aqui no SAMU, porque se você não for um psicólogo jamais vai acalmar uma família. (João)

Equipe de união, se não tiver união, algo vai errado. Se trabalhar em equipe dificilmente sai errado, se sair errado, a gente conserta. A gente procura sempre acertar, porque qualquer erro perde uma vida. Não pode se estressar, o estresse contamina. (Pedro) 
Vê-se, nessas falas, a importância da força do coletivo, caracterizada pelo entrevistado Thiago, ao se referir à equipe de trabalho. Quando ele enuncia que "somos uma equipe: o que dá para um dá para todos", evidencia a ideia de um trabalho coletivo movido por valores do bem comum. Em termos ergológicos, “[...] isto quer dizer que a questão do viver junto e sua determinação têm um sentido e uma significação para as pessoas." (SCHWARTZ; DURRIVE, 2010, p. 164)

Por outro lado, sobressai a importância de um relacionamento saudável com a chefia, já que os motoristas se deparam com situações, nem sempre exitosas, com usuários em atendimento e acompanhantes. É visível o sentimento de reconhecimento por parte dos entrevistados quando os usuários valorizam o seu trabalho. Uma vez mais, notamos a presença dos valores do bem comum, especialmente aqueles da ordem do ajudar outrem, salvar vidas.

\section{Eixo 5 - A dimensão dos valores no trabalho}

Por último, apresentamos os relatos que exploram a mobilização dos valores - dimensionados e não dimensionados - presentes na atividade de trabalho dos motoristas de ambulância entrevistados. Convém lembrar que tais valores, analisados pela perspectiva ergológica, contribuem significativamente para o debate sobre a atividade desses profissionais, porquanto exploram as experiências individuais e coletivas do trabalho realizado em atendimento de urgência e emergência móvel ${ }^{4}$.

Vê a pessoa precisando de ajuda pra mim é muito importante, me sinto realizado fazendo esse trabalho. (José)

Depois se vê o sentimento, depois que passou a situação porque você não pode se envolver com a situação e às vezes bato no ombro e digo que fiz minha parte. (João)

Já ganhei presente por ter salvo vida. Vem aqui só dar dá um abraço na gente, apertar na mão da gente [referindo-se ao usuário recuperado]. Aí já ganhei o dia de trabalho. (Pedro)

Com vida e depois qualidade de vida, primeiro a vida da pessoa depois qualidade, se ela torar uma perna e ficar viva pra mim é gratificante, se ela perder um braço e ficar viva pra mim é gratificante ter salvado essa vida, a qualidade de vida depois, o ruim é se ela morrer na mão da gente, então primeiro vida, salvou a vida, ela pode ficar sem as duas pernas, os dois braços, mas ela tá viva, ela vai agradecer depois por estar viva, depois a qualidade de vida que vem em seguida né? (Marcos)
Você faz a ocorrência, você pensa que pode ser um próximo seu, aí cai a ficha, a gente não quer que nada aconteça com ninguém. (João)

Esses últimos relatos dão conta do essencial da atividade dos motoristas de ambulâncias: o salvar vidas. Essa dinamicidade, atribuída à noção de vida, não é distante do conceito de saúde. Na concepção de Canguilhem (2005, p. 44), "[...] a saúde não é somente a vida no silêncio dos órgãos, é também a vida na discrição das relações sociais”. Em outros termos: viver com saúde, para além de uma simples ausência de doença, representa um valor imensurável no trabalho desses profissionais.

Nota-se, sobretudo na fala de Marcos, a valência de suas ações para manter os usuários com vida, mesmo que a sobrevida, após um acidente, por exemplo, classificado por ele como qualidade de vida, não proporcione vitalidade ao acidentado. É, portanto, o valor da vida de um humano que está em jogo. Ao conseguir resgatar usuários com vida, os motoristas também potencializam seu valor de vida para salvar outras pessoas. Entretanto, conforme relatado antes, enfrentam situações de impotência quando não conseguem resgatar/salvar usuários em atendimento. Enfim, eles vivenciam o conflito, o drama, já assinalado por Schwartz (2000) e Schwartz e Durrive (2010), dos usos de si (mais de si por si) para dar conta, de corpo e alma, do trabalho de salvar vidas.

\section{Considerações finais}

Neste artigo, analisamos a atividade e sua gestão no trabalho de motoristas de ambulância a partir do debate de normas e valores em diferentes situações de trabalho vivenciados por esses profissionais. Ficou evidenciado que os motoristas atribuem valores, geralmente não dimensionados, como vida, saúde e solidariedade durante as ações enfrentadas no trabalho.

A ausência de valores dimensionados (econômicos, produtivos) pode ser relacionada à natureza do trabalho de urgência e emergência móvel. Em outras palavras, é difícil para o SAMU estabelecer metas de produtividade em termos de números de atendimento, seja para mais ou para menos.

Apesar das situações emanadas no trânsito, das condições insatisfatórias e geradoras de impotência da ação no trabalho, os motoristas encontram apoio no esforço conjunto da equipe de trabalho (aqui traduzido como coletivo). Por isso reforçamos a importância da perspectiva ergológica ao postular a capacidade humana de criar novas normas de trabalho

\footnotetext{
4 Procuramos conduzir as entrevistas dialógicas de tal forma que pudéssemos facilitar nosso debate com os entrevistados sobre os valores a serem apreendidos.
} 
(renormatizar) com base nas normas antecedentes (experiências individuais e coletivas) mobilizadas nessa gestão do trabalho.

Ao refletir sobre a pesquisa que realizamos, nos apercebemos que teria sido de grande valia se tivéssemos realizado, além das entrevistas, Encontros sobre o Trabalho (SCHWARTZ; DURRIVE, 2010), que permitiriam que os debates entre os motoristas (e não apenas deles com os pesquisadores) ocorressem. No entanto, os limites de tempo de nossa pesquisa, aliados ao receio que tivemos de encontrar grandes dificuldades de reuni-los para a realização de tais dispositivos, deixou de fora essa possibilidade. Permanece, então, o desejo que em uma futura aproximação a esse grupo de trabalhadores possamos utilizar tal dispositivo.

\section{Contribuições de autoria}

Pinto, F. M.: formulação do projeto de pesquisa, execução e análise dos dados, elaboração do artigo. Zambronide-Souza, P. C.: contribuição na análise e interpretação dos dados da pesquisa, contribuição importante na sua revisão crítica e aprovação da versão final publicada.

\section{Referências}

AMBRÓSIO, P.; GEIB, L. T. C. Sonolência excessiva diurna em condutores de ambulância da macrorregião norte do estado do Rio Grande do Sul, Brasil.

Epidemiologia e Serviços de Saúde, Brasilia, v. 17, n. 1, p. 21-31, 2008.

BRITO, J. Trabalho prescrito e trabalho real. In: GLINA, D. M. R.; ROCHA, L. E. (Org.). Dicionário da educação profissional em saúde. Rio de Janeiro: EPSJV, 2006. p. 282-294.

CANGUILHEM, G. A saúde: conceito vulgar e questão filosófica. In: ___ Escritos sobre a medicina. Rio de Janeiro: Forense Universitária, 2005. p. 35-48.

. O normal e o patológico. Rio de Janeiro:

Forense, 1995.

CAPONI, S. Georges Canguilhem y el estatuto epistemológico del concepto de salud. História, Ciências, Saúde-Manguinhos, Rio de Janeiro, v. 4, n. 2, p. 287-307, 1997. http://dx.doi.org/10.1590/S010459701997000200006.

CÉLIA, R. C. R. S.; ALEXANDRE, N. M. C. Aspectos ergonômicos e sintomas osteomusculares em um setor de transportes de pacientes. Revista Gaúcha de Enfermagem, Porto Alegre, v. 25, n. 1, p. 33-43, 2004.

DARSES, F.; MONTMOLLIN, M. L'ergonomie. Paris: Éditions La Découverte, 2006.

GUÉRIN, F. et al. Compreender o trabalho para transformá-lo: a prática da ergonomia. São Paulo: Edgard Blucher, 2001.

MARQUES, S. R. Os efeitos do ruído em motoristas de ônibus urbanos do município de São Paulo. 1998. 118 f. Dissertação (Mestrado em Distúrbios da Comunicação)-Pontifícia Universidade Católica de São Paulo, São Paulo, 1998.
PEREIRA, W. A. P.; LIMA, M. A. D. S. Atendimento pré-hospitalar: caracterização das ocorrências de acidente de trânsito. Acta Paulista de Enfermagem, São Paulo, v. 19, n. 1, p. 279-283, 2006.

ROCHA, D.; DAHER, M. D. C.; SANT'ANNA, V. L. A. A entrevista em situação de pesquisa acadêmica: reflexões numa perspectiva discursiva. Polifonia, Cuiabá, v. 8, n. 8, p. 161-180, 2004.

ROSSI, C. G.; ROCHA, R. M.; ALEXANDRE, N. M. C. Aspectos ergonômicos na transferência de pacientes: um estudo realizado com trabalhadores de uma central de transportes de um hospital universitário. Revista da Escola de Enfermagem (USP), São Paulo, v. 35, n. 3, p. 242-248, 2001.

SANCHES, R. G. A problemática do ruído urbano: descrição e análise da literatura. 2003. $63 \mathrm{f}$.

Dissertação (Mestrado em Fonoaudiologia)-Pontifícia Universidade Católica de São Paulo, São Paulo, 2003.

SANTA CATARINA (Estado). Secretaria de Estado da Saúde. Regimento interno SAMU 192/ SC. Florianópolis: Secretaria de Estado da Saúde, 2012. Disponível em: < http://samu.saude.sc.gov. br/phocadownload/Rotinas/Rotinas_Estaduais/ regimento_interno_samusc.pdf $>$. Acesso em: 27 out. 2014.

SCHWARTZ, Y. Concordence de temps? Le travail, le marché, le politique. In: ___ _. Le paradigme ergologique ou un métier de philosophe. Toulose: Octarès Editions, 2000. p. 505-516.

. Os ingredientes da competência: um exercício necessário para uma questão insolúvel. Educação \& Sociedade, Campinas, v. 23, n. 65, p. 101-138, 1998.

. Trabalho e gestão: níveis, critérios e instâncias. In: FIGUEIREDO, M. et al. (Org.). Os 
Labirintos do trabalho. Rio de Janeiro: DP\&A Editora, 2004. p. 23-33.

. Trabalho e saúde: construindo outros modos de gestão. In: CONGRESSO BRASILEIRO DE CIÊNCIAS SOCIAIS E HUMANAS EM SAÚDE, 3., 2005. Florianópolis. Anais... Florianópolis: Abrasco, 2005. CD-ROM.

SCHWARTZ, Y.; DURRIVE, L. (Org.). Trabalho e ergologia: conversas sobre a atividade humana. Niterói: EduFF, 2010.

SILVA, G. L. L.; GOMEZ, M. V. S.; ZAHER, V. L. Perfil audiológico de motoristas de ambulâncias de dois hospitais na cidade de São Paulo - Brasil. Arquivos
Internacionais de Otorrinolaringologia, São Paulo, v. 10, n. 2, p. 132-140, 2006.

TAKEDA, E.; ROBAZZI, M. L. C. C. Occupational accidents among ambulance drivers in the emergency relief. Revista Latino-Americana de Enfermagem, Ribeirao Preto, v. 15, n. 3, p. 439-445, 2007. http:// dx.doi.org/10.1590/S0104-11692007000300012.

TEIGER, C. L'approche ergonomique: du travail humain à l'activité des hommes et des femmes au travail. Education permanente, Paris, n. 116, p. 71-96, 1993.

WISNER, A. A inteligência no trabalho: textos selecionados de ergonomia. Tradução Roberto Leal Ferreira. São Paulo: FUNDACENTRO, 1994. 